\title{
Techniques for upgrading educational standards in tourism: how to integrate business circles into university research?
}

\author{
V. B. Agranovich ${ }^{1, a}$, L.G. Kiryanova ${ }^{1}$, M.P. Zavyalova ${ }^{2}$, V.G. Melnikova ${ }^{2}$, P.A. Arlyapova ${ }^{1}$ \\ ${ }^{1}$ Tomsk Polytechnic University, 634050 Lenin Avenue, 30, Tomsk, Russia \\ ${ }^{2}$ Tomsk State University, 634050 Lenin Avenue, 36, Tomsk, Russia
}

\begin{abstract}
Methodology of developing modern educational standards has to comply with the new economic trends. Meeting the requirements of the market is conditioned by the integration of higher professional education and business all over the world. For the implementation of this integration strategy it is efficient to use the module education principle. This paper considers the main components of the module educational program: projective, innovative, and learner-centered. It has been shown that integration of business into research university programs can provide the necessary synthesis of theoretical and practical aspects of training professionals in tourism.
\end{abstract}

\section{Introduction}

The relevance of this study is justified by the fact that in the present circumstances the importance of tourism to the economy of Russia cannot be overestimated. Unfortunately, Russian economy is still based on the primary commodities. Under the circumstances, tourism becomes a mechanism of reorientation of the economy from the primary path to the path of innovation. Therefore, the role of training and retraining of internationally competitive professionals for the tourism industry would become particularly important as an adequate response to the challenges of our time. Methodology of developing modern educational standards has to comply with the new economic trends. Meeting the requirements of the market is conditioned by the integration of higher professional education and business all over the world. For the implementation of this integration strategy it is efficient to use the module education principle.

The research problem consists in the question of how to ensure the integration of theoretical and practical training in tourism educational programs in the process of upgrading CPE standards.

The problem of business-education collaboration and partnership is explored by many international authors as M.J. Mayhew, J.S. Simonoff, W.J. Baumol, B.S. Selznick, S.J. Vassallo, R. Johnson, S. Severance, W.R. Penuel, H. Leary, K. Lee, J. Hope, F. Abdulghani, G.B. Murphy, N. Tocher and others [1,2,3.4].

The vast body of research on problem-based learning (PBL) in Russia was made by such scholars as A. Nesterenko V. Larionov, N. Maksimov, O. Golitsyn.
Larionov defines the problem-oriented training of future doctors-dentists as an interactive cooperation among the subjects of the learning process, using operational management methods and means of training for creative independent work of students, which is the basis for the effective educational and research activities, focused on case studies and problem situations. This type of training is aimed at teaching a skill of solving non-standard professional problems that occur in professional activity [5]. The methodological basis of problem-based learning is a competence and contextual approach. The situational approach, as a leading one, is aimed at the formation of the students' knowledge and skills by the analysis of a concrete situation. The situational approach uses applied situational exercises, case studies, specific situations (case study method), when students must offer one or more solutions. Within the situational approach there is an accent put on the "subject-subject" relationship between students and teachers. Scientists reveal the content of the situational approach differently. According to V. Serikov, the situational approach is associated with designing such a way of life of the trainees, which is adequate to the nature of the personal development of the individual. A. Hutorskoy believes that the basis of the situational approach is an educational situation as a situation of "educational tension" that occurs spontaneously or organized by a teacher, and needs to be solved by joint efforts of all the participants. M. Ilyazova introduces the concept of the "situational-contextual approach as an approach to the formation of professional competences that determine the design and implementation of training professionally-oriented situations, reflecting the nature,

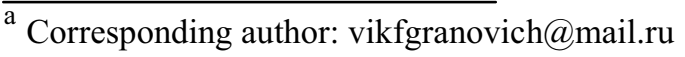


content, elements and components of the professional activities of the specialist.

In this article we made the analysis of the existing Russian CPE standards in tourism, and suggested the ways to upgrade them combining the international and domestic experience. We also tried to prove that such notion as "education - research - innovation" should be seen as a triangle of knowledge that will enhance the ability of universities to take part in joint projects with entrepreneurs in order to develop of the tourist market.

\section{Materials and methods}

The methodology of this study is multi-disciplinary and it consists of:

1. Principles, categories, methodologies of the comparative approach (monitoring of international and domestic experience of upgrading the educational standards of training for the tourism industry).

2. The categories of the program-target approach.

3. Qualitative content analysis methodology.

4. Quantitative content analysis of Internet resources in order to analyse domestic and international experience of inclusion of entrepreneurship into the research programs of universities.

5. An expert survey in the form of in-depth interviews. Experts were recognized representatives of the tourism industry, employees of travel companies, employees of regional administrations of the Russian Federation, representatives of public-private partnerships, and representatives of international tourist associations.

This paper has investigated the opinions and requirements of the following communities:

* The educational community (through the analysis of the effectiveness of the existing Russian practice of APE programs in the field of tourism);

* The business community and representatives of the authorities of tourist regions (through the use of the competency approach to educational programs, the focus on qualification requirements for professions and positions, the revealing of specific features of tourism development in Russia and the relevant tourist policy);

* Potential students (on the basis of existing core competencies and capabilities of students of additional educational programs and retraining programs).

We believe that this study will help to develop a mechanism for upgrading of educational standards in the tourism sector to include entrepreneurship in the research programs of universities.

\section{Results and discussion}

Most of the advanced countries with consumer societies form their budgets on the basis of sale of services. It should be noted that these are not the basic services related to meeting immediate needs, but services produced by the new economy - the Economy of the Senses. The formula of such a service: basic service + emotion. This approach allows overcoming the competitive situation in a crowded marketplace of services by creating a new market niche.
Tourism in this respect is particularly interesting, as it presents a range of services. It includes 4 components (by analogy with the four $\mathrm{P}$ of the marketing mix): transportation, food, lodging and display. Thus, it becomes clear why tourism plays a special role - tourism development will help to stimulate the development of several industries at once.

In order to enter the highly competitive market of tourist services, it is necessary for Russia to use innovations, as they are able to accelerate any process, and Russia has to overcome a significant backlog. We need to clarify what we mean by innovations. As we have said, tourism is a complex of services. Any service addresses the need; therefore, to define the concept of "innovation" we should correlate it with the concept of "need". In this context, to innovate is to create the needs that are not relevant to the individual at the moment. The new economy needs are not being studied, and then met. The innovative approach is that consumers are offered a service which is not related to their urgent needs. A consumers' decision to purchase must be irrational, focusing not on the price - performance ratio, but on the number of positive emotions they will get. The irrationality of a choice allows winning the competition on the market.

In such circumstances, the nature of management of the tourist enterprise is changing dramatically. In this regard, it is appropriate to quote the words of P. Drucker "When we talk about the new economy, we mean a world in which people work using their brains instead of their hands. A world in which innovation is more important than mass production." [6].

The driving forces of the new economy are:

1. Globalization in scientific and technical developments, technologies, production, trade, finance, communication and information, which has led to open economies, global interdependence and hyper competition;

2. Continuous, rapid and complex changes that create uncertainty and reduce predictability;

3. Knowledge, which has become the intellectual capital and a strategic factor; (a set of concepts used by people to make decisions).

In the new economic conditions, knowledge has become the major factor in the entire system of service production, due to the fact that it (as systematic data) changes the whole modern service industry. Knowledge - is a non-material resource, which largely determines the success of a company on the competitive market.

Under the circumstances, a special role is played by the system of additional professional education (APE), which aims to train highly qualified professionals to meet the growing staffing needs of the dynamic Russian tourism industry $[7,8]$ by means of:

- involvement of new personnel in tourism from other sectors of the economy;

- development of competencies acquired while working in the tourism sector;

- acquisition of new competencies in the field of modern tourist organizations, products, processes and technologies $[9,10]$.

The main objects of tourist professional activity are: 
- customers (individual or corporate clients) and their needs;

- tourism product;

- service technology in tourism;

- results of intellectual activity in the tourism sector;

- intangible assets owned by the subjects of the tourist industry exercising the rights of ownership or other legal basis;

- accommodation, catering, facilities, excursion activities, sports and recreation services, vehicles, and other objects associated with the development and implementation of the tourism product;

- automated information systems and technologies.

The monitoring of stakeholders' requirements for the competences of professionals in tourism (conducted by the authors) has shown that the system of additional professional education (APE) should be based on a synthesis of entrepreneur experience of trainees and research programs of universities. Such a synthesis will provide for the integration of theoretical and practical aspects of training in tourism, and for cohesion and consistency of the educational process.

The APE key principles are: a focus is on the trainee, team work, variability of disciplines, an interdisciplinary approach, activation of prior knowledge, achievement of the boundaries of understanding, an ability to formulate problematic issues, an independent search of information, providing feedback. Using entrepreneurial experience of trainees in the APE programs is related to wide use of interactive forms of training in class (interactive seminars, discussions, computer simulations, business and role-playing games, case studies, psychological and other training) combined with extracurricular work. This educational technology helps to create and develop the professional skills of trainees. As part of the training course (one-third of the course), there should be provided meetings with representatives of Russian and international companies, representatives of state and public organizations, workshops of experts. [8].

To achieve this goal the Russian-European consortium of universities, regional authorities and travel companies initiated a project, which in October 2012 received approval and funding within the program "Tempus" of the European Commission. The mission of the project is to support sustainable development of the Russian regions through the development of an international network of "universities - authority business" in the field of tourism and hospitality, to promote the harmonization with EU policy in the field of education and training in general and continuing education in particular in the target Russian regions. The project deals with the development of a network "universities - authority - business" for continuing education in the field of tourism and hospitality and covers four Russian regions: Tomsk, Altai, Kemerovo and Ivanovo.

The basis of this approach in APE can be Problem Based Learning (PBL). This approach involves finding solutions of real-life problems, which encourages students to study as they can see the result. The problemoriented approach is more effective than traditional teaching, since the knowledge, used in the context of the problems to solve, appears as more valuable than the one that can be found only in the structure of different disciplines.

Thus, the purpose of problem-based learning is not overloading students with a large amount of facts to memorize, but carrying out a research, aimed at solving a real-life problem, which is taken from the entrepreneurial experience of students themselves. Students can use the text of the task, the problem description, the procedure (order of operations) of solution, as well as any necessary material, they think is useful to clarify the issue. Students work in groups of 10-13 being observed by an instructor, who has different functions such of a lecturer or a teacher. The problembased learning method is based on performing of certain types of work.

The task is a starting point of the PBL-method. The task contains a description of the problem. Tasks can be either theoretical or practical.

There are the following types of work:

- problem tasks represent a description of the problem of the specific business area manager, or the director of the organization that provides services. This is the most common type of work;

- discussion tasks are issues for discussion;

- strategic tasks imply developing a strategy for behaviour in certain situations;

- references for the study refer specifically to the material that should be studied and the way it should be done;

- tasks intended for performing specific actions represent specific instructions for meetings, interviews, information gathering, and so on;

- application tasks require the application of existing knowledge to a specific task.

Since the problem situation may go beyond the traditional framework of a single discipline, this PBL approach can be easily used in a modular program. The use of modular programs, based on competences in the system of additional professional education, is conditioned by the integration process of higher education in the world [7].

This approach has the following advantages:

1) constant feedback from potential employers to find out the requirements for knowledge, skills and abilities of employees;

2) development of knowledge and skills in the formation of specific competences is integrated within the same module, in contrast to the traditional approach, which studies one subject (module) without its relations with other knowledge and skills;

3) students have an opportunity to receive continuing education, learning to be responsible for their own studies, and in the future - for their own professional growth and career;

4) the theoretical and practical components of the training are integrated, which allows reconsidering the place and the role of theoretical knowledge in the development of competencies, their ordering and systematization, which ultimately leads to increased motivation of students for their learning; 
5) the opportunity to quickly update or replace modules if specific requirements change because of changes in technology and work organization;

6) the opportunity to use the same modules in several training programs;

7) the opportunity to personalize learning for each student based on his/her level of knowledge and skills and prior experience by combining the necessary modules;

8) control of the quality of education includes not only the amount of knowledge learned, but also the level of competence developed.

The modules are complete "portion of knowledge and skills", and include all components necessary for learning, from the learning objectives up to the final examination and evaluation of the module by students.

The program provides a fixed set of compulsory modules. According to the thematic interdisciplinary approach there is a key theme at the center of each module, which combines all the disciplines of the module and all forms of work. It sets the general direction of the training module and determines the subject area and the corresponding set of disciplines.

All disciplines in the module are interconnected and complement each other, so there is no "major" subject, but instead there is the integration of subject areas required to solve specific practical problems faced by a travel professional.

The integrative and modular approach helps to consider the educational material within the module, not only as a whole, but also as a structural unit, welded inside by the interdisciplinary integration. This approach has the following components, which are components of the educational process (integratives):

- «Project" integrative provides the integration of theoretical knowledge and practical skills through the implementation of a method of projects. This integrative includes application of projects which have been conducted and tested.

- "Innovative" integrative is aimed at teaching a travel professional innovative thinking. This integrative should be implemented by including materials about innovations in tourism such as product innovation and innovation technologies.

- «Person-centered" integrative suggests such organization of learning which allows students to gradually build their individual career path. This integrative involves individualization of the educational process, formation of the professional role behaviour, development of self-presentation skills.

The integrative and modular approach allows achieving the following goals of training:

- in the process of interdisciplinary integration a tourist professional can be educated representing 3 main characteristics: as a professional, as an intellectual and as a researcher;

- in the process of inter-subject integration each discipline is studies based on the relationship with other disciplines;

- in the process of interpersonal integration the cooperation of students and teachers helps to solve complex problems of professional training, development and education;

- in the process of intrapersonal integration professional and personal readiness to work in the field of tourism is formed, and it can be evaluated as a number of specific skills: methodological, theoretical, methodical, organizational, communicative and reflexive.

\section{Conclusion}

The results of our study have shown that absolutely all the representatives of the tourism market agree that there is a need for modernization and development of vocational education in the field of tourism. Several experts noted that education should be more standardized, i.e. there must be universal standards in accordance with which the staff, trained within the same educational programs in tourism, would have a comparable set of professional knowledge and skills. On the other hand, training should be more narrowly focused, i.e. there is a need for specialized courses aimed at obtaining the narrow knowledge, such as knowledge of the regulatory framework of tourist activity. We also emphasize that business representatives noted the need for practical orientation of the content of educational programs. Graduates must be prepared to work in a real tourism market. To introduce a practice-oriented approach in education, it is necessary to build close relationships among business representatives and the education community, such as the introduction of methods of problem-based learning, master classes conducted by leading international experts, joint work of the business community and students on tourist projects to develop the domestic tourism in the region.

The result of this study complemented with the requirements of potential consumers of tourism services (the further research is planned by the authors) will help to identify the main directions of the modernization of APE programs in tourism.

\section{References}

1. M.J. Mayhew, J.S. Simonoff, W.J. Baumol, B.S. Selznick, S.J. Vassallo, Journ. of High. Edu, 87 (3), (2016)

2. R. Johnson, S. Severance, W.R. Penuel, H. Leary, Journ. of Math. Teach. Edu, 19, 2-3 (2016)

3. K. Lee, J. Hope, F. Abdulghani, Eval. and Progr. Plann, 55, (2016)

4. G.B. Murphy, N. Tocher, B. Ward, Pub. Organiz. Rev., 16 (1), (2016)

5. V.V. Dis. Dr. Ped. (Sci.: Mosc, 2008)

6. P.Drucker, 3d Intern. Compet. Conf., Royal Lancaster Hotel, (London, 1998)

7. M.M. Mihaylova, Pskovski regionologichesky zhurnal, 11, (2011)

8. M.I. Shevchenko, Intern. Resear. Conf. (Mosc., 2011)

9. N.A. Kolodiy, E.V. Rodionova, V.B. Agranovich, Mod. Prob. of Sci. and Edu, 2, (2013) 
10. E.V. Rodionova, N.A. Kolodiy, T.V. Konyukhova, Mod. Prob. of Sci. and Edu. 2, (2013) 